\title{
A Three-Stage Model of Digital Transformation
}

\author{
Jiaqi $\operatorname{Jin}^{1, *}$ \\ ${ }^{I}$ Faculty of Natural \& Mathematical Sciences, King's College London, Strand, London, WC2R 2LS, United Kingdom \\ ${ }^{*}$ Corresponding author. Email: k20072782@kcl.ac.uk
}

\begin{abstract}
Digitalization brings convenience to the world and changes the business landscape. However, the scope of structural change that digitalization brings about goes to much broader business practices, for example, how firms begin digital transformation has received little attention. In this paper, I study the practices and separate the digitalization practice into three stages. Due to the uniqueness and interdependence among those three stages, digital transformation becomes continuous and processual. This theoretical model will guide us to analyze the digital transformation of business group. I make our contributions to existing research on the empirical setting as well where one entity goes through the three stages and how it carries out. I switch focus from platform economy to the way to digital transformation of traditional firms, expanding the influential scope of digital technologies and answering the practical issues. Besides, this paper also discusses the application in furniture industry. This paper will lead to findings that can motivate more research on how firms implement their digital transformation.
\end{abstract}

\section{Keywords: Manufacturing Firms, Digital Transformation, Three-Stage Model, Furniture Industry}

\section{INTRODUCTION}

With the vigorous development of digital technologies such as artificial intelligence, big data, cloud computing and mobile Internet, a new digital era has arrived. Digital economy has also become an important new potential economy, which provides impetus and technical support for the innovation and upgrading of China's real enterprises. Using the listed firm data from 2012 to 2017, this paper investigates the performance enhancement effect of the digital transformation of real enterprises. Through sample analysis, it is found that China's digital economy policies have a great impact on the performance of digital transformation of real enterprises, and digital innovation and upgrading have significantly improved the economic benefits of real enterprises. In May 2018, the Cyberspace Administration of China released the Report on China's Construction and Development (2017). The scale of China's digital economy reached 27.2 trillion yuan in 2017, up 20.3 percent year on year, accounting for 32.9 percent of GDP, according to the report. The scale of the digital economy in 2018 was 31.3 trillion yuan, accounting for 34.8 percent of GDP, according to the White Paper on the Development of China's Digital Economy in Employment in 2019 released by the China West-line Communication Research Institute. At the policy level, the State Council made it clear in the "13th
Five-Year Plan for the Development of National Strategic Emerging Industries" released in 2016 that it would vigorously support emerging industries including "Internet plus", cloud computing, big data, Internet of Things, and intelligent manufacturing. With the arrival of the $5 \mathrm{G}$ era, the "industrial digitalization, digital industrialization" has accelerated the development, promoted the reconstruction of life, production, process and mode, and provided more possibilities for the Internet of everything. The scale of the digital economy is rapidly expanding, and the world has entered the era of digital economy. In the digital economy, emerging technologies are two points, digital transformation is the focus, and real enterprises are the main battleground. To comply with the call of the digital economy era and better promote the digital change has become a new mission and new opportunity on the shoulders of entity enterprises. As an important part of the "digital economy", the digital transformation of real enterprises can best reflect the actual operation of the digital economy by focusing on the "digital" behavior and economic consequences of a single economic organization in the market. Centering on the topic of "digital change", a series of academic literature has been formed, which can be divided into the understanding of "digital change", the economic consequences of "digital change", and the transformation path of "digital transformation" according to different topics. This paper will take the digital innovation and 
upgrading of furniture industry in the real economy as an example to study the theoretical model and discuss the transformation path of digital innovation and upgrading in different industries.

\section{LITERATURE REVIEW}

International experience shows that in the digital transformation, entity enterprises are the main battlefield, and industrial integration is the key. China should grasp the new generation of information technology follow the law of industry development, strengthen the planning guide for policy support, create conditions to arouse enthusiasm of entity enterprise in digital revolution, promote the mobile Internet, big data and cloud computing, artificial intelligence and the depth of the real economy, ease barriers to entry, exaggerate the market subject equality into range, release continuously dividend policy to promote change and increase the benefits change. On the road of digital transformation of physical enterprises, focusing on reducing costs is one of the effective ways to improve the performance of digital transformation [6]. Before the comprehensive transformation of real enterprises, it is necessary to continue to maintain the "three removal, one reduction and one supplement" to resolve the pressure of digital transformation of real enterprises and provide a good external environment for reducing costs and burdens. Entity enterprise should realize this path to realize the important role of digital transformation of the enterprise benefit, make full use of digital information, insight into market to get rid of unnecessary intermediate links and optimize internal processes and the allocation of resources, improve the ability of rapid response to customer demand, by lowering the transaction costs and operating costs to achieve economic benefit of ascension .In terms of time factors, the interconnection of data and information, and the acceleration of changes in the external business environment, it is difficult for enterprises to maintain their competitive advantages. With the advent of the new digital era, the success of digital innovation and upgrading is a choice between life and death for enterprises. For consumers, digital technology has released their time, and they have more leisure time to develop their interests and potential according to their own characteristics. The expansion of time dimension makes consumers' demand for services/products more personalized. From the perspective of spatial elements, digital technology transfers physical stores to virtual network space, and the types of goods that can be displayed are no longer limited by physical space, which helps enterprises better cope with the phenomenon of long tail demand. For consumers, relying on the Internet, geographical location is no longer a factor limiting consumption. The most typical example is the emergence of Alibaba and Jingdong e-commerce, which greatly facilitates consumers' shopping behavior and also changes people's shopping habits. From the perspective of connecting elements, the links between enterprises, product direct, consumer direct, and product/consumer and enterprise are far more abundant than in the past [5]. The interaction between supply chain members in virtual space is more frequent, and it is easier for enterprises to get in touch with new trading partners; More and more intelligent Internet products, so that between products, between products and enterprises, between enterprises increasingly close contact; For consumers, they can only maintain limited social network relationships in traditional offline relationships, while the social cost in virtual space has dropped significantly, which leads to a much greater number of connections in virtual space than in real life. With the application of big data and the transformation of digital innovation, time, space, connection and other elements in the virtual environment have undergone qualitative changes compared with the physical environment. It should be pointed out, however, that these two links coexist rather than oppose each other, and only the degree of entity and virtual environment varies in different industries. The emergence of digital virtual environment, on the one hand, expands the scope of the traditional enterprise operation management mode, and it is necessary to take these changes into account in the optimization of operation management mode. More importantly, these changes can create opportunities, create value, and innovate the way we manage our operations [9].

In the process of digital development of physical enterprises, it is necessary to promote the improvement of quality and benefits, and the operational efficiency advantages formed based on big data will become a new engine for performance improvement. We should continue to promote the market-based allocation of data elements, speed up the reform of fiscal, taxation and financial systems, and form a digital ecosystem that is conducive to the quality and efficiency of real companies, so as to provide favorable conditions for digitalized enterprises to improve their performance. Entities should seize the opportunities of digital transformation, dig deep into the value of big data, use the integration and cosharing characteristics of data and information to reconstruct their internal business portfolio, synergistic mode and management level, explore specialization and lightweight operation, and strengthen supply quality and efficiency, so as to better promote performance growth. In addition to enhancing the quality and efficiency of supply, we should strengthen the innovation drive. Innovation is the key driving force of digital transformation, and the application of new technologies and technologies is an important measure for real enterprises to replace old drivers of growth with new ones and move towards a stage of high-quality development. China should accelerate the innovation system based on information construction, entity enterprises as the main body and market orientation, promote the development and application of advanced digital technology, and 
realize the construction of "Digital China" driven by Chinese digital technology. At the same time, enterprises in digital transformation should actively use digital technology and cross-border integration to cultivate new products, new business forms and new drivers, explore the path of element-driven transformation to innovationdriven transformation, break the distorted barriers in the allocation of production factors, enhance data value creation, and better walk in the forefront of high-quality development through reform and innovation [8]. Based on the above theoretical basis and the economic background of The Times, the theoretical model of the three stages of digital transformation of real enterprises will be studied in detail.

\section{THREE-STAGE MODEL OF REAL ENTERPRISE TRANSFORMATION}

\section{Stage 1: Big data collection and interconnection}

The first step in the digital transformation of physical enterprises should be the interconnection of everything and the interconnection of data and information. Application of various new technologies in business applications and the integration of new management models. For example, shared bikes are the integration of two-dimensional code technology, positioning technology, intelligent terminals and the morning process of shared bikes. In the process of convergence, large amounts of data are generated, and corresponding data analysis methods have important potential value in creating transparency, discovering customer needs, segmenting market, supporting decision making, and innovating business models/products/services. Enterprises need to apply emerging digital technologies, build a "centralized" data platform serving the government and organizations in the industry, break down the data barriers in the industry, and complete the large-scale construction of data. Data scale construction, must be clear resource identification, access and transformation and other German importance. And the use of new technology is one of the common means of resource identification and acquisition. Digitalization and related technologies will not only improve efficiency, but also create new business models and define new competitive paradigms, thus subverting the existing process of enterprise operation management and bringing about innovation of operation management model.

Stage 2: Platform based on data resources

Apply digital technology according to data resources to open the platform of interconnection between people, people and things, and things and things. From the perspective of typical practice, the business ecosystem built by mature platforms such as Alibaba, Didi Chuxing, Meituan, 58.com, Ganji, Ctrip, etc., is developing and popularizing the business based on data resources through the digital transformation of products, services and management processes. Platform construction can bring more effective and higher value services to enterprises, and users of the platform can also create value based on organizational interaction. The value of the traditional manufacturing industry to create a digital environment is mainly manifested on consumers, suppliers, wholesalers and retailers with intelligent terminal, online platform, virtual design links such as digital platform jointly participate in the design of the slopes, the production, storage and sales, to break the traditional manufacturing mode between enterprises and consumers, enterprises, the barriers between the manufacturers can also through the digital technology continuously improve products, better meet the diverse personalized needs of the customers.

\section{Stage 3: Digital economy ecosystem}

On the premise that the platform breaks the data barrier, the construction of the digital economy ecosystem is carried out. With the popularity of mobile Internet and the change of consumption habits, consumers increasingly hope to be able to meet various types of needs in a one-stop, seamless way, through a simple interface or click can complete a series of consumption activities. For example, functions such as ordering meals, buying tickets and navigation can be realized on the same platform, or the temperature, lights and speakers can be controlled through a mobile phone application. Faced with such multi-type, multi-function and integrated requirements, it is often difficult for a single enterprise to fully realize them. With the support of new technology, the design of the product or service, production, warehousing, distribution, after-sales service and other links in the global scope of the Internet virtual supply chain, suppliers, manufacturers, wholesalers and retailers can be involved in different supply chain, and even to assume different functions in different supply chain, play to the role of the different, the same members may appear as consumers in some of the supply chain, but in other suppliers' role in the supply chain. Under such a background, the traditional linear structure of "supplier producer - wholesaler - retailer - consumer" vertical supply chain has been subverted. Enterprises and individuals from different industries, different functions and different regions form a complex "relationship chain" based on the Internet platform. Leading companies are relying on the Internet, cloud computing and other technologies to connect previously unrelated products or services to form a networked and dynamic ecosystem to create and meet the integrated needs of consumers. Members of the ecosystem can be upstream and downstream enterprises similar to the former members of the supply chain, or they are more likely to be previously unrelated enterprises reflected in the digital environment. For example, the smart home ecosystem makes routers, televisions, speakers and other products intelligent and provides services to consumers in a seamless way. At the same time, the formation of the ecosystem also changes 
the previous competition mode, which is based on the data, service and product package provided by the entire ecosystem to create value for consumers, rather than a single enterprise in a certain part of the ecosystem to achieve profits. In the future, the business competition will no longer be the survival of a single enterprise, but will be transformed into the competition between different economic ecosystems in the same industry. For example, Alibaba and Jingdong in e-commerce are playing games on the basis of economic ecosystems. In order to win the competition in the ecosystem, enterprises must think about such issues as what kind of ecosystem to join and what role to play in the ecosystem. Navigation apps like Waze have great value in delivery, e-commerce, taxi hailing and other services, so they have the potential to become an important part of the corresponding ecosystem. Table 1 describes the key characteristics of the three stages.

Table 1 Key Characteristics of Three Stages

\begin{tabular}{|l|l|l|l|}
\hline & First stage & Second stage & Third stage \\
\hline Developing target & $\begin{array}{l}\text { Integrating data } \\
\text { resources }\end{array}$ & Setting up a centralized platform & $\begin{array}{l}\text { Establish an economic } \\
\text { ecosystem }\end{array}$ \\
\hline Developing pattern & $\begin{array}{l}\text { Setting up a data } \\
\text { system }\end{array}$ & Break down information disunity & $\begin{array}{l}\text { Cooperate with companies } \\
\text { in the industry }\end{array}$ \\
\hline Key technology & Big data & Platform technology & Integrated date \\
\hline Main obstacles & Data collection & Squeeze the user & Information asymmetry \\
\hline Example & & e.g. Alibaba & e.g. Feixin \\
\hline
\end{tabular}

\section{THE APPLICATION OF THEORETICAL MODEL: FURNITURE INDUSTRY AS AN EXAMPLE}

In the context of the full-scale outbreak of COVID19 in 2020, for the purpose of prevention and control of COVID-19, governments of various countries have taken home quarantine measures one after another, enabling people to live a "home" life, and home has become the main place for people to study, work, entertainment and shopping. During the epidemic prevention and control period, people study and work at home, and people's demand for household products skyrocketed, which had a great impact on the furniture industry. According to global traffic analysis by international supplier Mapp, online orders for the furniture industry during the outbreak prevention and control period increased by 17 percent compared to pre-outbreak levels at the beginning of the year.Consumption has become the primary driving force for our economy to stretch. According to the statistics of China's Ministry of Commerce, in the past six years, the contribution rate of consumption to economic growth reached 57.8 percent. The sudden rise of the digital economy under the normality of the epidemic is expected to become a new way to boost consumption.Consumers can consume goods and enjoy services through the Internet at home, which is characterized by strong individualization, high flexibility and low participation threshold. Therefore, some industries and enterprises are forced to accelerate the pace of transformation to "online + current price".In this process, traditional enterprises and digital economy to enjoy the benefits, but also faced with many challenges, many industries have begun to change the road of regional development. This paper takes furniture industry as an example again to discuss this issue.

In the first step of digital transformation in the traditional furniture industry, an integrated logistics information platform should be established. With the development of information technology, the potential of large logistics system and integrated service has been fully tapped, and an information platform has been built to provide enterprises and consumers with more efficient, accurate and comprehensive integrated service of furniture logistics. This platform will directly contact furniture enterprises, integrate transportation resources and installation master resources through the back end, and complete the supply chain system of the new city. The front end is consumer-oriented, and can match orders, transportation and warehousing visualization, distribution, installation and after-sales service, credit risk assessment and other value-added high-quality services throughout the year to provide comprehensive optimization solutions for furniture logistics. The application of digitization and related technologies to optimize the internal operating system and improve operational efficiency. Traditional furniture enterprises often find it difficult to trace the information of raw material collection, production and processing, storage management, logistics and transportation. Therefore, blockchain technology has broad application potential in the digital transformation of the furniture industry. A supply chain with complete commodity quality tracing system is constructed by combining commodity transaction information with new source information, which makes the data of each process of furniture visualized, portable and controllable, and realizes real-time monitoring and all-round tracking of furniture quality. In addition, the enterprise in addition to the production process, process, its equipment, product resources, decision-making system will be realized system alley, data interconnection [5]. Digital epochmaking enterprise Jinzheng has changed from the big fish eat small fish to fast fish eat slow fish mode. So-called faster than, is able to quickly adapt to the customer, market, competitive environment changes of the enterprise. In order to gain competitive advantage within 
an enterprise, it is particularly important to create an agile, fast decision making and high-performance group support mode. Internal information of a digital enterprise needs to be spread rapidly at the organizational level. Therefore, the enterprise needs a multi-functional and integrated command center to enhance the ability of the organization to perceive and respond to external requirements. In the process of digital transformation, part of the principal-agent problem of the new organizational form may disappear, business owners will no longer need agents to complete certain transactions, and complex transactions can be completed in the blockchain-dominated system. The nature of the human resources that need to be managed within the organization will change, and employees with digital and analytical skills may replace existing employees. Therefore, enterprises themselves should also carry out digital innovation and upgrading. The construction of a reasonable and efficient organizational structure can become the source of strategic assets and competitive advantages for enterprises to integrate organizational resources under the background of digitalization, which plays a key role in the development of enterprises. This ability to build, need to have faith, strategic commitment and investment, short-term science can not see the return; However, once the capability is built up, it will contribute to the medium and long term development of the enterprise.

In the second stage of digital transformation of physical furniture industry, the construction of digital display platform for home products based on virtual reality technology should be established.The main function of the digital display platform for furniture products based on virtual reality technology is to display household products. Users observe the three-dimensional model appearance of furniture products according to their preferences and demands, and obtain the main performance parameters of furniture products at the same time. Users can obtain product functions through more complex virtual interactive experience for the home products they are interested in. Based on this, the threedimensional modeling of home products needs to strive for lifelike, while virtual reality technology provides interesting online furniture product operation by means of human vision or hearing. Users can acquire the actual sense of home products at any time in the space environment, thus stimulating the enthusiasm of buying home products. The digital display platform of furniture products based on virtual reality technology can not only provide intuitive and civilian interactive experience, but also have the function of free roaming, so that users can fully immerse themselves in the virtual reality scene. The platform features are as follows: (1) Design a virtual furniture sales shop. All furniture products in the shop can be displayed in the virtual environment. Users can interact with it through corresponding operations, so as to get a roaming sense similar to that in the furniture sales shop; (2) Carry out 3D modeling of household products. Household product 3D modeling is the main content of virtual furniture sales shops, TV users gain real experience, the 3D modeling and rendering of household demand is higher, add the human-computer interaction function at the same time, through the sensory stimulation to show the user home products such as video animation performance, users can more in-depth understanding of the performance of household products; (3) Design objects such as walls, ceilings, floors and display tables in furniture sales stores to enrich users' visual senses and roaming experience; (4) Design lighting effect of digital display scene of furniture products.

Digital display of furniture products is one of the main forms of furniture sales in the future, which is to build three-dimensional models of furniture products by computer technology and present them in front of users by display terminals, so as to realize the interaction between users and furniture products and feel the same experience in the real world. The establishment of the platform system will enable enterprises to obtain far richer data types and quantities than in the past. In addition to transaction data, it can also record users' browsing, purchase, use, evaluation and other data, including search keywords and page residence time, etc. These behavioral characteristics are often the direct expression of user preferences and personalized needs. Combined with strong data analysis ability, customers' needs can be more accurately predicted and the potential value of data can be better mined. For example, when recommending application download, the system considers downloading and browsing behaviors, and based on the "involvement theory", it can better understand customer needs and make Jin Jin recommendation. Further, and then based on the predictions of a data application and promotion, the operations management decisions such as order, also need to pay attention to the decision variables for the results, the influence of many times given direct correlation historical data mining does not guarantee can get good decisions or predict performance, need to learn a causeand-effect relationship between decision variables and results can effectively intrusive decisions. However, based on a large number of consumer usage data of the platform, it is possible for enterprises to accurately design products that are more in line with user needs, with better performance and higher efficiency. For example, through data analysis, Staccato stores found that the try-on rate of a new shoe ranked first one week after its launch, but the order conversion rate was $3 \%$, far lower than the average level. After the actual investigation, it was found that the writing shoelace was too long. Based on the results, the shoe was sent back to the factory for improvement. When it was relaunched in March, the writing conversion rate reached $20 \%$, and the single product generated tens of millions of sales, becoming the No. 2 seller in the spring and summer [9]. With the help of digital technology, 
furniture entities can make more optimized pricing and inventory decisions. In terms of pricing decisions, firstly, by learning from data, enterprises can dynamically optimize pricing strategies and achieve better revenue management. While development platforms are crucial, they are not the only ones. It is worth noting that enterprises also have behaviors to be avoided in the process of building platforms and optimizing pricing strategies. For example, in the network hotel reservation platform, the emergence of the old users than new users expensive phenomenon. In this process, the enterprise fills part of the price information for the old users, and makes use of information asymmetry to enable the old users to make decisions without important information. This kind of differentiated pricing based on digital technology does more harm than good to the long-term development of the enterprise.

The third stage of the digital transformation of the physical furniture industry is to establish its own good ecological environment and economic ecosystem. The digital age not only expands the industrial boundary, but also changes the underlying logic of business competition. Number since the transformation is a process of traditional business relationship refactoring, reconstruction after the new mode of commercial relationship has redefined the enterprise - product - user roles, represent a stronger link, more interactive, more dimensions of value creation mode, has become the enterprises in the digital revolutionaries the key to win the competitive advantage. First of all, the competition among platforms is no longer a zero-sum game, and how to expand the market through the ecosystem of strong alliances has become the key to platform competition. Establish a data open platform for cross-organization interaction based on data resources, that is, a platformbased business ecosystem. Entity furniture enterprises should invite different institutions in the industry to cooperate and jointly construct an industry-oriented centralized data platform in the form of signing confidentiality commitment, confidentiality agreement and other forms to maintain the basic rights of partners, purchase or exchange conditions such as designing web pages for the organization, background operation and making big data analysis reports for the organization. From suppliers - producers - wholesalers - retailers, the whole supply chain structure is working with them to build a healthy conscience and positive development of the new economic ecosystem. Taking the furniture industry as an example, in the case of promoting the economic ecosystem, it should not be limited to a single brand, but the whole furniture industry should be unified and integrated, and furniture enterprises with different materials should be integrated into an economic ecosystem. In doing so, it will quickly expand or swallow up other companies in its industry. Mutual cooperation between different entities furniture enterprises, to create value, mutual information resource sharing, data will be more rapidly increase the size of the data, when the data volume continues to rise, after the economic ecosystem of platform guide will be able to more macro perspective on the potential value of the mining data and by that time because of wrong information, etc., within the industry and in economy ecosystem to hit the outside of the enterprise, thus to establish a new economic ecosystem importance, should be mutual cooperation between enterprises, seeking to create value.

\section{CONCLUSION}

Even in the beautiful future development environment of the digital era, not all physical enterprises can succeed in digital transformation. The road of digital transformation is still full of mud and frustrations, and physical furniture enterprises still have many problems to face. Many enterprises pay too much attention to the development of the platform and constantly explore the new profit model of the platform, which is on the wrong path instead. In the process of digital transformation, entity enterprises are the main battlefield, and ecommerce will not completely replace the offline model. The virtual world will always need the support of the physical world. Especially for the furniture industry, every stage of digital transformation is crucial. According to the theoretical model, this paper has been applied to the furniture industry from a macro perspective, but there are still many details that have not been discussed. I hope that other scholars will improve my theory.

\section{REFERENCES}

[1] Zhou Yi. Research on Digital Display Platform of Furniture Products Based on Virtual Reality Technology [J]. Modern Electronic Technology, 201,44(03):172-176.

[2] Wang Jingxian, Liu Honghai. Development status and trend of furniture e-commerce $[\mathrm{J}]$. Ecommerce,2020(11):36-37.

[3] TANG F. Changes of household industry in the next ten years [J]. China Forestry Industry,2020(11):6871. (in Chinese with English abstract)

[4] Qiu Yizhou, Zhang Zhongfeng. Challenges and Opportunities for the Development of Furniture Enterprises under the Economic Background of "Residence" [J].Furniture \& Interior Decoration,2020(11):16-18.

[5] Wang Weinan, Yan Zichun, Mei Liang, Chen Jin. The evolution of platform enterprises based on data resources -- the enlightenment of Feiyou Technology [J]. Economic Management,2020,42(06):96-115.

[6] Chen Dongmei, Wang Lizhen, Chen Anni. Management World,2020,36(05):220-236+20. (in Chinese) 
[7] Chen Jian, Huang Shuo, Liu Yunhui. From enablement to enablement: enterprise operation management in digital environment [J]. Management World,2020,36(02):117-128+222.

[8] Wang Yi, Qiu Guodong. Research on Multiple Intelligence Organizations under the Background of New Industrial Revolution: A Case Study of GE and Haier [J].Economic Management,20,42(02):92-105.

[9] He Fan, Liu Hongxia. Evaluation on performance enhancement effect of digital transformation of real enterprises from the perspective of digital economy [J]. Reform,2019(04):137-148. 